\title{
Beyond markets and states: the importance of communities
}

\author{
Bart Engelen
}

Most contemporary social scientists - be they economists, sociologists, or political theorists assume that people in their roles as citizens, politicians, and public servants act in ways that serve either their self-interest or the public interest. After explaining more fully this motivational dichotomy (first section), I aim to show that this has led to a separation in conventional normative debates on institutional design, which have focused on the proper division of

Bart Engelen is a Postdoctoral Fellow of the Research Foundation - Flanders (FWO) and is currently affiliated to the Centre for Economics and Ethics of the K.U. Leuven (Belgium). His research mainly concerns ethics and political philosophy, with a particular interest in rational choice theory, public choice theory, voting behaviour, and the motivational and evolutionary sources of cooperation.

Email: bart.engelen@econ.kuleuven.be tasks between markets and states (fourth section). Here, however, I want to stress the importance of phenomena that do not fit these motivational and institutional dichotomies. Focusing on the widespread motivation of strong reciprocity (second section), I aim to show the importance of communities in the institutional schemes of modern societies (fifth section). The general argument that underlies both lines of reasoning is that different explanatory models of people and their motivations generate different views of the good society and how to institutionally design it (third section). Next, I make some general suggestions in order to support and enhance communities so that they can help to achieve socially desirable outcomes (sixth section). In the final section, I formulate a conclusion.

\section{The motivational dichotomy: self-interest and public interest}

The implicit presupposition in the bulk of social sciences is that people, when making decisions in the public domain, are motivated by the public interest, no matter how it is defined. Sometimes it is understood along the lines of a general will - as Jean-Jacques Rousseau does - explicitly assuming that people try to find out what this entails and how to realise it. ${ }^{1}$ Even if it is understood as some function of private interests - as social choice theorists do - people who work in governmental institutions are trusted to further these interests. Often, these political philosophers have a dual image of people, modelling them as self-interested within the private realm of the market and as public-spirited within the public realm of the state. Rousseau (1983, p.26), for example, argues that "each individual can, as a man, have a private will contrary to or different from the general will that he has as a citizen. His private interest can speak to him in an entirely different manner than the common interest". John Rawls and other social contract thinkers try to bring together private and public interest by devising some form of original position, which puts self-interested people in an 
impartial stance so that they take heed of the public interest.

James Buchanan, founder of both positive and normative Public Choice theory, criticises exactly this ambiguity. Instead of assuming publicspiritedness, which he deems a sign of grave naivety, Buchanan (1999, vol.x, pp.53-75) consistently models peoples as self-interested in all spheres of their lives. In his view, people are no different in their public roles as citizens, politicians, and public servants than in their private roles as consumers and producers. They systematically attempt to extract as much benefit as possible from the bureaucratic apparatus and use whatever power they have to influence policies to their own advantage. Stressing such rent-seeking behaviour, Buchanan (1999, vol.x, pp.38-52) thus criticises the romantic view of the state as a benevolent despot, which has implicitly dominated modern political theorising.

Julian Le Grand (2003, p.27) describes both extremes of this motivational dichotomy in terms of knaves and knights: "knaves can be defined as self-interested individuals who are motivated to help others only if by so doing they will serve their private interests; whereas knights are individuals who are motivated to help others for no private reward". He rightly stresses that both types of motivations are present in the public domain: "people can behave as knights, and indeed frequently do so, even in situations where their actions are diametrically opposed to those that would further their self-interest. Moreover, these motivations appear to be prevalent among providers in the public sector, although interacting in complex ways with more self-centred motivations" (Le Grand 2003, p.38). While self-interest is not completely absent from the public domain, knightly motivations should not be ignored (Le Grand 2003, p.118).

In addition, the general thrust of recent developments in micro-economics has led theorists to increasingly move away from narrow models of people as (primarily) self-interested towards broader models of people, attempting to fulfil their preferences, whatever these might be. It can be argued that these trends have increasingly made the motivational dichotomy irrelevant, since social scientists now understand that both self-interested and public-spirited motivations are structurally similar. Whether people act in order to serve their private interest or the public inter- est, they aim to serve a specific goal (or interest, for that matter). As such, both motivations are part of people's instrumental reasoning. Moreover, other distinctions have recently been made by economists and other social scientists, such as between deliberate, reasoned behaviour on the one hand (as in models of perfect rationality) and unreflective behaviour on the other hand (as in models of bounded rationality). ${ }^{2}$ While these theories are interesting, I nonetheless believe that they do not invalidate this dichotomy. Much of what has been and is still being written in the social sciences continues to hinge upon the distinction between self-interested (or self-regarding) and public-spirited (or other-regarding) preferences. In this respect, I would like to take part in the growing literature criticising this dichotomy that regrettably still lingers in models and theories of human motivation.

\section{Beyond the motivational dichotomy: strong reciprocity and social norms}

The basic problem with this motivational dichotomy is that most people's spectrum of motivations is not limited to such a continuum. While some people indeed seem to fit (a mix of) these models (Fehr and Gächter 2000, p.162; Gintis 2000, p.316), a majority of people act in radically different ways. These people are motivated by strong reciprocity, which can be defined as "a propensity to cooperate, respond to cooperative behaviour by maintaining or increasing co-operation, and respond to noncooperative free-riders by retaliating against the 'offenders', even at a personal cost" (Gintis 2000, p.313). Experimental evidence suggests that at least half of all people are strong reciprocators in this sense (Bowles and Gintis 2002, p.F425; Kahan 2005, pp.344-345).

Strong reciprocity is not some mix of selfinterest and public-spiritedness. On the other hand, it lies beyond the motivational dichotomy: "people are not generally the self-interested actors of neoclassical economics, since they value treating others fairly and will incur personal costs to do so. Nor are people the unconditional altruists of utopian thought, since they want to hurt free-riders and other norm-violators" (Gintis 2000, p.316). In contrast with the latter, who cooperate no matter what, strong reciprocators cooperate only if others 
do their fair share as well. In contrast with selfinterested people, who freeride no matter what, strong reciprocators are prepared to take on costs even if this yields no personal gain whatsoever. Their willingness to punish freeriders is altruistic, since it benefits the group they belong to but not themselves. This distinguishes strong from weak reciprocators, the latter reciprocating only if it brings about benefits in the short or the long run. Strong reciprocators cooperate with others similarly disposed even in conditions where such benefits simply cannot arise, like one-shot interactions in complete anonymity (Fehr and Gächter 2002, p.139). Strong reciprocity thus cannot be understood in outcome-oriented terms. Whereas both self-interest and public-spiritedness constitute goals for people to reach, strong reciprocity refers to the importance people attach to internalised social norms (Kahan 2005, p.343). Their adherence to norms, which often prescribe prosocial behaviour, explains their willingness to cooperate and their tendency to punish those who violate such norms, whether this serves their self-interest or not. Such norm-guided behaviour should not be understood as means towards the realisation of their goals but as principles and commitments they consider as important.

Social norms are informal guidelines, shared by the members of a group, which specify which actions are regarded as socially desirable and which are not. Here, I define norms as psychological propensities that can, in some cases, impede the rationality of people's decision-making processes. Against the general tenor of conventional economics, which is to define rationality in self-interested and outcome-oriented terms (Pettit 2002, p.226; Sen 1987, pp.1-15), I want to argue that actions are rational if they arise from what people consider to be good reasons. In this light, strongly reciprocal and norm-guided behaviour can indeed be understood as rational (Gintis et al. 2005, p.5; Le Grand 2003, p.28). Whereas this conception of rationality focuses on the reasons that actually cause people to act, conventional economists typically stress that actions are rational if they satisfy people's preferences, whether or not they deliberately aim to do so. Such a conditional methodology - a person acts the same way as she would do if she aimed to serve her goals - is inappropriate when it comes to explaining truthfully individual behaviour. According to Bernard Williams (1990, p.392), as if statements "can be true independently of the agent's motivations. But nothing can explain an agent's (intentional) actions except something that motivates him so to act". The fact that there might $b e$ a reason for an action does not necessarily mean that this action is performed for that reason. A person's beliefs and desires are reasons for her actions, only if they play a role in causing them. ${ }^{3}$ Similarly, actions might be in the self-interest of an individual, even though they are not performed out of self-interest.

While granting that actions can be motivated by purely self-interested or purely public-spirited motivations, my point is that strong reciprocity cannot be reduced to one of these extremes or to some composite of both. In this respect, I refer to the model of a Homo reciprocans who "cares about the well-being of others and about the processes determining outcomes - whether they are fair, for example, or violate a social norm. He differs in this from the self-regarding and outcome oriented Homo economicus" (Bowles and Gintis 2000, p.37). Homo reciprocans is not primarily selfregarding or other-regarding but values the fairness and justice of the process itself of the social interactions. In my view, such a model complements the all too narrow models that constitute the motivational dichotomy.

I want to make clear that I understand each of these models as ideal types: abstractions that highlight certain aspects of individual motivation. Real-life individuals are seldom motivated purely by egoism, public-spiritedness, or strong reciprocity. Instead, their motivational array typically consists of a whole gamut of considerations that interact and intermingle with each other and gain different weight in different contexts. Rather than aiming to provide a completely truthful picture of real-life people, however, my strategy here is to distinguish conceptually certain features of human motivation. In my view, the motivational heterogeneity that characterises people suggests (rather than contradicts) the value of a plurality of explanatory models that complement rather than replace each other.

As such, these models are - like most scientific models - false in that they violate both the whole truth (they are partial representations at best) and nothing but the truth (they are false even in the things they aim to represent). Yet, they can be said to highlight specific features of the real world (human motivations) by excluding or neutralising other features, which are typically 
assumed to be absent or negligible (Mäki 2005). By way of idealising assumptions (like ceteris paribus clauses), these models isolate people's self-interested, public-spirited, and strongly reciprocal motivations and thereby provide partial yet truthful representations of parts of human psychology. My criticism of the motivational dichotomy between self-interest and public-spiritedness is therefore not that it is false but that it leaves out a feature of human motivation that is prominent in the majority of real-life people. Complementing this dichotomy with strong reciprocity thus makes the resulting picture less partially and more truthfully representing people's motivational array.

In my view, most people have a general predisposition to follow the social norms they have internalised up to the point that it becomes too costly. Even though they typically do not deliberate in explicit self-interested terms, such considerations have a virtual presence and can gain weight in specific situations. People act on the basis of a more or less automatic pilot, only to shift when it becomes too costly. Then, selfinterest kicks in and takes over the wheel (Pettit 2001, p.86). While the Homo economicus model thus has a role to play in explaining behaviour, it is not the central role that has been imputed to it. My main quarrel with both the worst-case scenario of universal egoism and the naïve assumption of universal public-spiritedness is not that they are not completely reflecting real people - after all, no model is - but that their assumptions fail to isolate even those features that are essential to human motivation (explanatory purpose). As I will show in the next sections, such models therefore form inapt starting points for institutional design as well (normative purpose).

\section{Deriving normative implications from explanatory models}

Welfare economists and normative political philosophers aim to think up desirable institutions and policies. In this respect, I want to focus on the role of explanatory models in justifying different institutions and policies: "assumptions concerning human motivation - the internal desires or preferences that incite action $-\ldots$ are key to both the design and the implementation of public policy" (Le Grand 2003, p.2). According to Buchanan
(1999, vol.x, pp.60-61), who stresses the need for a uniform model of individual motivation and behaviour to compare and evaluate different institutional schemes with each other, it is safe to assume self-interest rather than benevolence on the part of individuals in their public roles. Buchanan's central dictum is that of David Hume (1964, p.42) who urged that "in contriving any system of government and fixing the several checks and controls of the constitution, every man ought to be supposed a knave and to have no other end, in all his action, than private interest". Partly due to Buchanan, this self-interested Homo economicus has become the standard model in theories of institutional design (Le Grand 2003, p.9). This led to a general predilection for markets over states (as I will show more fully later on), but it also cleared the ground for the carrot and stick approach in which policies are designed to promote the public interest by rewarding prosocial behaviour and punishing antisocial behaviour.

According to Buchanan (1999, vol.xii, pp.9899,106), these institutional and policy-related proposals are desirable even if not everybody acts in his self-interest. After all, it makes sense for you to lock your door even if only a fraction of all people are thieves. The assumption of self-interest is deemed appropriate for normative purposes even though it is known to be false (Hume 1964, p.42). In contrast, I claim that normative conclusions hold only if their underlying model of individual motivation and behaviour is true in a significant sense of the word (Kahan 2005, p.366). The argument is as straightforward as it is simple: "if the outcomes of institutions designed for knaves are much worse than the outcomes designed for actual individuals and the odds of everybody being a knave were low, then it would be foolish to choose the institutions designed for knaves" (Hausman 1998, p.74). Of course, it might be reasonable to design institutions and policies based on a realistic estimate of the proportion of people acting in a purely selfinterested manner, but taking into account only opportunistic citizens risks making everybody worse off.

If politics is really about people, it ought to be based on significantly true models of their behaviour (Bowles and Gintis 1999, p.3). What matters is which institutional design works best in practice, given the way real people act, which is why it should be based on empirically sound models of human motivation (Le Grand 2003, p.24). In the 
words of Jean-Jacques Rousseau (1983, p.17), one has "to inquire whether there can be some legitimate and sure rule of administration in the civil order, taking men as they are and laws as they might be". In this respect, I want to join John Rawls (1999, p.12) in his quest for "a realistic utopia" in which institutions and policies facilitate interaction among people as they actually exist. Such a scheme is realistic in the sense that it could work, given the way people are; it is utopian in the sense that it consists of an ideal that is not yet realised.

\section{The institutional dichotomy: states and markets}

In what follows, I intend to show that the motivational dichotomy, with its primarily explanatory purpose, has led to a dichotomy at the level of normative thinking about desirable institutions (Bowles and Gintis 2002, p.419). Here, I define institutions as relatively stable patterns of more or less formal rules, customs, practices, and traditions that help to organise, regulate, coordinate, and structure social interactions between the members of a society. Now, theorists who model people in their public roles as public-spirited tend to favour a rather pervasive state. If people serve the interests of others, they can be expected to agree on some public interest and are willing to pay any level of taxes needed to realise this. In addition, publicspirited politicians and bureaucrats can be trusted to do what is needed to serve this general goal, for example through the provision of public systems of education or health care. In contrast, theorists who model people as self-interested tend to be wary of governments, because they expect government officials to serve their private interests rather than the public interest. They tend to praise markets for their capacity to transform self-interested actions into socially desirable outcomes (Le Grand 2003, p.12). Markets and their invisible hand mechanisms can lead to mutually beneficial arrangements based on nothing more than the self-interest of the involved parties. This is the main reason why theorists like Buchanan (1999, vol.vii, pp.203-204, vol.xviii, pp.311-312) tend to favour laissez faire politics, in which the state is constitutionally constrained to a minimum level of action so as to avoid the excesses of unbridled rent-seeking and to prevent government officials from abusing their power for their own benefit. The state's only task is to allow markets to function properly and correct for their failures. Governments should provide incentives in order to solve collective action problems that arise when self-interested Homines economici freeride on other people's contributions and thus refuse to provide voluntarily public goods. Typically, the strategy here is to bridge the gap between private and public interests by rewarding compliant and sanctioning deviant citizens (Kahan 2005, pp.341-342).

In short, the institutional dichotomy that can be said to result from the motivational one consists of two contending camps "advocating laissez faire on the one hand or comprehensive state intervention on the other as the ideal form of governance" (Bowles and Gintis 2005, p.379). Of course, a number of alternatives are left out here. First, there is the Hobbesian argument that self-interested people need a state with absolute and unlimited authority to prevent a war of all against all. People mutually consent to such a Leviathan, because they realise that it is a necessary evil to make social life among knaves possible at all. However, I believe this position is inconsistent, since it implicitly assumes that (the people that embody) this Leviathan will take heed of the public interest and enforce peaceful coexistence, which runs counter the assumption of universal self-interest. Second, there are anarchists who argue that public-spirited individuals do not need a coercive state, since they will voluntarily achieve harmony. However, a society where order is achieved without rules or constraints is a romantic fiction (Buchanan 1999, vol.vii, pp.5-9). Since disagreement persists among publicspirited citizens as well - for example, on what the public interest consists of - some coercive enforcement mechanism is needed even here.

Lately, however, consensus has grown over the imperfect nature of both markets and states. Markets fail in achieving unanimously agreed upon goals because of freeriding problems and negative externalities. This situation leads governments to provide public goods and compensate those who suffer from externalities. However, because of rent-seeking behaviour, governments fail as well. As a result, normative debates on the ideal institutional structure of modern societies have focused on the extent to which markets and states can and should complement each other and how to achieve a proper task division between them. 


\section{Beyond the institutional dichotomy: the value of communities}

As shown above, the motivational dichotomy is best complemented by an alternative that models people as motivated by strong reciprocity. In what follows, I will analyse the institutional implications of the Homo reciprocans model. To do so, I want to stress the importance of a third kind of institution, namely communities. These are collections of people who see themselves as members of a group with a shared identity and a shared sense of relatedness (McMillan and Chavis 1986, p.4). Whereas markets and states are institutions in which interactions are typically formalised, largescaled, ephemeral, and completely anonymous, communities are groups of people who typically interact in more informal, direct, frequent, and personal ways (Bowles and Gintis 2005, p.381). In such networks, interactions are not primarily based on self-interest or public-spiritedness, but on the strongly reciprocal willingness to cooperate with others so disposed and to punish those who violate communal norms.

Placing communities next to markets and states does not imply, by any means, that these are the only three institutions in modern societies (Bowles and Gintis 1998, p.22). One could provide a much more fine-grained description of institutions like families, churches, and classes, which I will not do here, partly for reasons of space but also because I believe that the latter can be fitted within the broad category of communities quite well. That is also the main reason why I limit myself to the three institutions that have been called "basic structural institutions" (Christiano 2004, p.124). In short, these can be understood as different ways in which members of a society relate to each other. David Miller (1990, pp.17-18) aptly summarises this thought with this broad definition of communities: "As participants in a market, people's relationships are those of voluntary exchange. ... As citizens of a state, people's relationships are constituted by formal rules specifying what each is entitled and obliged to do.... As members of a community, people are related by ties of identity which give rise to informal obligations of mutual aid."

The core of communities is indeed formed by social norms, which are mutually supportive of strong reciprocity. Internalised norms of fairness, for example, induce the strongly reciprocal disposition to reward fair and punish unfair behaviour. And this disposition in turn helps to maintain such norms. By means of relatively costless monitoring and sanctioning by peers, communities can ensure that informal norms continue to motivate their members. Whenever contracts are incomplete or their enforcement very costly, ${ }^{4}$ informal norms are more rather than less efficient than the formally enforced contracts that typically govern relations in markets and states (Fehr and Gächter 2000, pp.168,178). Whenever freeriding behaviour threatens the achievement of socially desirable outcomes, norms are able to provide a (partial) solution to collective action problems (Bowles and Gintis 2005, p.384). In short, "communities solve problems that might otherwise appear as classic market failures or state failures" (Bowles and Gintis 2002, p.F422). This explains why - even in modern societies characterised by increasing individualisation - communities remain important in governing interactions: "communities have properties allowing them to persist in a world of market exchanges and modern states despite their inability to exploit the efficiency-enhancing properties of markets and the advantages of universal enforcement of rules provided by states. Among these properties ... is the capacity of communities to avert or attenuate costly coordination problems of the prisoner's dilemma type" (Bowles and Gintis 1998, p.22).

Communities can vary with respect to a number of variables, like group size, cohesiveness, shared characteristics or goals, membership criteria, and so on. ${ }^{5}$ While it is possible to make conceptual distinctions along these lines - which might give rise to a categorisation of associative, cooperative, traditionalist, and other sorts of communities - I focus here on what is shared, namely the informal and repeated nature of the implied interactions. While the claims I am making here are not necessarily to be understood as communitarian in the sense of anti-liberal, my emphasis on the need to revalue communities (in the broad sense of the word) is shared by so-called political communitarians who criticise both left (statist) and right (libertarian) ideologies for eroding forms of communal life. Whereas too much focus on the bureaucratic state apparatus shifts power away from communities, too much focus on markets implies "the extension of instrumental considerations governing relationships in the marketplace 
into spheres previously informed by a sense of uncalculated reciprocity and civil obligation" (Bell 2009).

Particularly worrisome about such pressures is the distinguished capacity of communities to overcome problems with freeriding. This allows their members to achieve high levels of cooperation on a largely voluntary basis, thereby avoiding costly enforcement schemes (Bowles and Gintis 1998, pp.4-5). Confronted with freeriders, strong reciprocators either stop cooperating or punish them when this is possible. Two possible scenarios thus follow. First, cooperation can start to unravel when more people increasingly refuse to contribute. If others no longer cooperate, why should I? Subjects in experiments can indeed stop contributing when they feel unfairly treated and have no other means to punish freeriders. Second, cooperation can be upheld when freeriders are punished by strong reciprocators who take on costs in order to express their moral outrage at the fact that they are being treated unfairly. In both cases, the presence of strong reciprocators is crucial and thus has to be taken into account when searching for institutions that organise social life in modern societies.

Next to this purely instrumental defence of communities, one can also argue that they have intrinsic value as well. People are social creatures who define themselves as members of groups. Seeing their origins and destinies as inextricably associated with the groups they belong to, they feel isolated without them. Communities therefore make up a significant part of people's lives and their deeply-rooted identities (Miller 1990, p.234). Communal interactions are based on people's identification with a shared history, tradition, language, or symbol (McMillan and Chavis 1986, p.8). In contrast, because of their anonymous nature, markets and states do not allow people to act on those parts of their identities they consider as important (Bowles and Gintis 1998, p.6). Communities thus form the only institutional constellation that can enable people to express who they are and can provide an antidote to the possibly alienating contexts of markets and states. Whereas the latter are explicitly based on the liberal goals of mutually beneficial cooperation and neutrality, communities provide individuals with possibilities to act on their comprehensive doctrines.

This is especially important given the increasing threat of individualisation, which is prominently present in both the market sphere (where capitalism has reduced the importance of informal economies) and the public sphere (where people increasingly form anonymous masses). Communities have the potential to counteract these evolutions and attenuate the widespread negative effects of the dissolving bonds between the members of a society. Take the example of care for the elderly. Whereas this used to be done on a voluntary basis by family members and neighbours, individualisation has urged the need for more formalised public arrangements. These have downsides, like the increased costs for society in general and, more importantly, the deteriorating well-being of the elderly themselves. After all, placement in large homes often leads to increased isolation and depression. Here, both the instrumental and the more intrinsic value of communities come to the fore.

Before making some rather general suggestions on how to support and strengthen communities, I want to stress that all is not necessarily great about them: "communities work because they are good at enforcing norms, and whether this is a good thing depends on what the norms are" (Bowles and Gintis 2002, p.F428). Surely, norms generally prescribe prosocial behaviour towards fellow community members. Characterised by high entry and exit costs, communal interactions typically occur on a repeated and long-term basis. As a result, members in general tend to treat each other decently (Bowles and Gintis 1998, pp.3-8). Nevertheless, communities heavily rely on the distinction between insiders and outsiders. Membership always has boundaries: some people belong and others do not belong to the community at hand (McMillan and Chavis 1986, p.4). If based on race, religion, or sex, this inherently exclusive rationale can lead to morally repugnant situations. That is why governments are needed to enforce rules that ensure the respect of human rights, thereby helping communities in governing social interaction. Nevertheless, it is important and possible to empower communities, while avoiding their possibly perverse logic of $u s$ versus them (Bowles and Gintis 2002, pp.F431-432). After all, communities can exist at the level of the nation state as well: even though identification with smaller communities can be more intense, nationality often constitutes an important part of people's identity. ${ }^{6}$ In this sense, communities and states can mutually reinforce rather than exclude each other. 
Applying the argument that models of individual motivation have normative implications, I have shown that the Homo reciprocans model, which lies beyond the conventional motivational dichotomy, supports community governance, which lies beyond the conventional institutional dichotomy (Bowles and Gintis 2002, p.F421). While the Homo economicus model focuses on mutually beneficial cooperation arising from market exchanges and governmental insurance mechanisms (Bowles and Gintis 1999, p.4; 2000, p.38), the Homo reciprocans model stresses cooperation that is based on a perceived balance between rights and obligations (Bowles and Gintis 2000, p.44). Most people feel that justice requires the benefits and burdens of public arrangements to be distributed fairly and thus more or less evenly. Here, the issue is how to help communities in achieving their socially desirable outcomes.

\section{How policies can support rather than undermine communities}

If communities perform generally desirable functions for members of a society, the question of institutional design which then arises concerns the policies that can be developed to revalue them and to make sure that they are not further weakened. Here, I want to suggest a number of ways in which government policies and communities can turn out to be mutually supportive of each other.

First, take the example of redistributive government interventions, which are perceived as fair and legitimate when they favour people who are not responsible for their own suffering, like the poor who do not deserve to be poor. The other side of this coin is that most people do not support such policies, if they favour people who make no effort whatsoever to engage in socially valued work. There is some truth in the cliché that hardworking taxpayers do not like being duped by lazy people who choose not to work. The perceived legitimacy of welfare programmes thus crucially depends on "one's views of why the poor are poor, and specifically one's beliefs about the relative importance of effort rather than luck" (Bowles and Gintis 2000, p.47). Whenever people oppose welfare policies, it is typically not because they do not want to pay for them, but because these policies offend their strongly reciprocal adherence to norms of justice and fairness: "policies that reward people independent of whether and how much they contribute to society are considered unfair and are not supported" (Bowles and Gintis 1999, p.16). Strong reciprocity is thus crucial for policy-makers who aim to implement measures that really affect people's lives. This not only suggests what policies might ultimately aim for (a fair distribution of benefits and burdens) but also provides a valuable resource to get there.

To show its relevance for governmental policies, one can simply stress the fact that strong reciprocity induces people to act against their selfinterest in their public roles as both politicians and citizens. First, politicians are constrained by norms which prevent them from using public resources to their own advantage (Kahan 2005, p.364). The public nature of their function requires them to justify publicly their behaviour, which cannot be done in purely self-interested terms. In this respect, Jon Elster (1998a, p.12) refers to the "civilising force of hypocrisy". At first, the norm that politicians refer to in the public interest might induce hypocrisy (civilising speech). Later, cognitive dissonance reduction mechanisms lead them to adjust their opinions to their speeches (civilising minds) (Elster 1998b, p.104). The nature of democratic politics can thus ultimately induce politicians to act honestly, sincerely, and impartially.

Second, strong reciprocity among citizens has repercussions as well for the design and enforcement of policies aimed at the provision of public goods. The conventional carrot and stick strategy of providing material incentives to align citizens' self-interest with the public interest may prove less cost-efficient than relying on informal norms to solve problems of collective action (Kahan 2005, pp.347-362). The public good of civil order, for example, is achieved voluntarily in communities, whereas it typically takes a lot of policing and enforcing in large-scaled and anonymous governmental contexts. Precisely because they generally prescribe prosocial behaviour, it is important not to undermine communities and their norms.

Moreover, conventional strategies can be counterproductive, because they risk weakening the engagements and commitments that motivate citizens. Material incentives can induce individuals to shift from their usual, norm-guided routines to more calculating attitudes. Material rewards and sanctions can increase the salience of selfinterested considerations. In addition, they can 
mask the motivations of fellow citizens, which may lead one to wonder whether or not they will continue to cooperate (Pettit 1996, pp.75-76). Why else would such incentives be provided? Empirical research indeed suggests that material incentives diminish and dissipate mutual trust, which can even undercut the positive effect of incentives altogether (Kahan 2005, p.343). Because voluntary norm-guided behaviour can break down once it is formally rewarded or sanctioned, the conventional strategy may turn out to be self-defeating. In other words, material incentives can crowd out strongly reciprocal behaviour. Similarly, markets and states can be said to crowd out communities (Gintis et al. 2005, p.20).

Such crowding out effects go against the assumption, shared by both models of the motivational dichotomy, "that the balance of motivations - the extent to which individuals are motivated to behave as knights or knaves - is independent of the policy structures themselves" (Le Grand 2003, p.40). In my view, both markets and states are likely to induce shifts in the motivations of its participants. First, it has been argued that markets corrupt since they tend to enhance self-interest and reduce altruism (Le Grand 2003, p.40). However, empirical evidence shows that "this is not an automatic consequence of introducing market reward systems, provided these are properly designed" (Le Grand 2003, p.168). Second, it can be argued that states rather than markets are to blame for turning knights into knaves. Crowding out of public-spirited behaviour can, for example, occur if state intervention fully compensates for the implied sacrifice (Le Grand 2003, pp.49,55). On the bright side, empirical evidence also suggests that financial stimuli can crowd in knightly behaviour if they are perceived as the symbolic recognition of socially valued activity. Take wages for public servants. If these are set too high, one risks attracting only those who are in it for the money, which would turn the assumption of universal selfinterest in the public domain into a self-fulfilling prophecy. If, however, they are set too low, the risk of corruption and bribery increases (Brennan 1996, pp.273-274). Putting aside where the middle road lies, which should be decided on an empirical basis, I simply want to stress that these considerations should be taken into account when designing policies.

The possible threat of knightly motivations being crowded out suggests the need to detect them and take measures to guarantee their continued relevance. As James Madison already wrote in his Federalist Paper no. 57: "the aim of every political constitution is or ought to be first to obtain for rulers men who possess most wisdom to discern, and most virtue to pursue the common good of the society; and in the next place, to take the most effectual precautions for keeping them virtuous" (Pettit 1996, p.81). Madison stresses the need to take into account a complex motivational array when designing institutions and also suggests an alternative strategy altogether. After all, it makes sense not only to entice self-interested people by providing material incentives but also to select people with the right motivations (Brennan 1996, p.272). If one accepts that not everybody is the same, it is reasonable to try and select the right person for the right job, like attracting publicspirited people for public functions. The insight of motivational heterogeneity thus opens up options that are unthinkable when simply assuming universal self-interest (Brennan 1996, pp.258-262).

Philip Pettit mentions two strategies to increase cooperation and avoid freeriding problems. The first and conventional one relies on material incentives. Pettit is aware that treating people as Homines economici may lead to crowding out: "the introduction of deviant-centered sanctions would tend to switch agents from a nonegocentric to an egocentric mode of deliberation. Conclusion: The introduction of deviant-centered sanctions is likely to do more harm than good" (1996, p.73). This leads him to favour a second strategy, which focuses on "a more ordinary sort of individual: someone who deliberates in most contexts in a nonegocentric way" (Pettit 1996, p.78). Here, policies are designed to support the forms of socially desirable actions that are performed on voluntary bases. This complier-centred strategy explicitly aims to fortify rather than undermine spontaneous compliance to norms prescribing knightly behaviour (Pettit 1996, pp.81-87). In short, governments save themselves a lot of trouble simply by welcoming and supporting the desirable outcomes of community norms.

Granted, some formal sanctions aimed at encouraging citizens to cooperate are effective. Some prevent completely lawless situations to arise. Moreover, if they explicitly target freeriding knaves and stress that knaves are the exception rather than the rule, they can bolster rather than undermine the widespread predisposition to 
cooperate (Kahan 2005, pp.346-351). What is crucial is that they leave intact the strongly reciprocal sense of fairness that guides norm-guided individuals. In short, "good policies and constitutions are those that support socially valued outcomes not only by harnessing selfish motives to socially valued ends, but also by evoking, cultivating, and empowering public spirited motives" (Bowles and Gintis 2002, p.430).

Crucial in this respect is the trust that citizens have in their fellow community members and in the institutions that govern their lives. If citizens trust each other to take on their fair share of the burden, they tend to cooperate more, making costly government interventions largely superfluous. And if the latter is needed, it is important that a vast majority of citizens complies (Richerson et al. 2003, p.377). Only then will policies generally be perceived as fair, just, and legitimate, which further harbours trust and renders costly incentive schemes partially obsolete (Gintis et al. 2005, pp.30,33). If, for example, almost everybody pays taxes, these come to be perceived as justified, which helps uphold high levels of tax compliance. If, however, people believe that an increasing number of citizens no longer contributes, compliance gradually erodes, leading to a further decline in the general inclination to contribute. In these cases, strong reciprocity overrules self-interest, which would spur people to evade their tax duties altogether.

\section{Conclusion}

The main purpose of this article has been to criticise and complement the motivational and institutional dichotomies that have dominated the social sciences but are blatantly inapt to account for a wide range of phenomena. When they fail to incorporate empirical evidence of people's strong reciprocal adherence to norms, conventional market-state debates turn to be grossly outdated and misinformed. The conception that people serve the public interest has recently been replaced by the less naïve view that individuals systematically serve their private interests. The resulting strategy of economising on virtue, however, is completely inappropriate, since virtue is not aptly conceived of as a scarce resource that is used up if employed too often. In fact, knightly motivations are likely to fade away if they are not put into practice on a regular basis.
In this respect, I have argued that both extremes of the motivational dichotomy are inapt for normative purposes. On the one hand, institutional design based on the assumption that people are knights is likely to cause disaster if most reallife people have more knavish motivations. On the other hand, institutional design based on the assumption that people are knaves can come to suppress real-life people's more knightly motivations (Le Grand 2003, p.2). A theoretically richer and empirically more adequate model of individual motivation that includes strong reciprocity is badly needed when thinking about the good society and how to improve its institutional design (Fehr and Gächter 2000, pp.161,178; Kahan 2005, p.366). While it needs to be developed more fully, I believe the Homo reciprocans model is an apt starting point. While I cannot, for reasons of space, provide an in-depth account of the kind of institutional design implied by such a model, I have made some general suggestions on the complex interaction between policies and communities. ${ }^{7}$

Like the explanatory models of individual behaviour and motivation, the institutions that I have described - markets, states, and communities - are best understood as ideal types that do not exist in a pure form. Real societies always consist of a complex mix of elements that characterise these ideal types. Indeed, the whole point is that none of these basic institutions can function properly without the help of the others. In the end, an amalgam of institutions can and should mutually complement and support each other in regulating social life (Miller 1990, pp.249-251). Given the mix of motivations that cause real-life people to act as they do, real-world societies should consist of a mix of institutions, each of which functions on the basis of these respective motivations. A governmental framework (states) is indispensable for the functioning of markets, just as much as informal community norms help govern the interactions between consumers and producers, employees and employers (markets), and citizens and their political representatives (states). Markets and states would simply break down without the widespread tendency of individuals to adhere to social norms. It should be clear therefore that the main challenge lies in "developing an institutional structure such that states, markets and communities are mutually enhancing" (Bowles and Gintis 2002, p.F431). After all, institutions can only fulfil their tasks if most members perceive them as fair and legitimate. 


\section{Notes}

1. It is conceptually useful to distinguish between publicspiritedness and altruism as two sorts of other-regarding motivations. Whereas public-spirited people aim at serving the public interest, altruistic people aim at serving the interests of concrete others. To be sure, the public interest can - but is not necessarily construed as the aggregation of the interests of all members of some group.

2. I thank an anonymous referee for urging me to go into this issue.

3. This also shows that the popular distinction between the natural sciences (which aim to explain the causes of events; Erklären) and the social sciences (which aim to understand the reasons behind events; Verstehen) is misleading in that the latter include a causal element as well. Social scientists who want to explain a person's actions should demonstrate that he has reasons for them and that these motivate him. Not only should there exist a reason for a particular action, the person should actually perform this action for that reason.
4. Examples are families, neighbourhoods and workplaces. Even though one might think that professional relations are typically governed by self-interest, research has shown that both employers and employees act on the basis of internalised norms of fairness and honesty, even when they know that opportunism would serve them better (Gintis 2003, p.164; Gintis et al. 2005, p.15).

\section{For one categorisation of} communities, see Bell (2009) who distinguishes between (1) "communities of place", based on shared geographical roots; (2) "communities of memory", based on shared histories; and (3) "psychological communities", based on shared ends and the face-to-face interactions needed to attain them. Other categorisations stress that some communal relations are freely chosen (as amongst club members) whereas others are not (as amongst family members or compatriots). Both classifications are in line with my broad definition of communities, which goes against the conventional definitions that usually exclude associations of choice. In their classic work Habits of the
Heart, Bellah and his co-authors (1985, p.335), for example, do not count so-called "lifestyle enclaves" as communities, because their members do not consciously share a specific past.

6. David Miller (1990, pp.238239) aptly describes the meaning of what a community at the national level entails: "what does it mean for people to have common national identity, to share their nationality? It is essentially . . . shared beliefs ... that each belongs together with the rest; that this association is neither transitory nor merely instrumental, but stems from a long history of living together which (it is hoped and expected) will continue into the future; that the community is marked off from other communities by its members' distinctive characteristics; that each member recognises a loyalty to the community, expressed in a willingness to sacrifice personal goals to advance its interests."

7. For a more detailed exposition of my views on institutional design, see Engelen (2008), especially pp.119-240.

\section{References}

Bell, D., 2009. "Communitarianism”. In: E. N. Zalta, ed. The Stanford encyclopedia of philosophy. Available at: http://plato.stanford.edu/ entries/communitarianism

Bellah, R. N., Madsen, R., Sullivan, W. M., Swidler, A. AND Tipton, S. M., 1985. Habits of the heart: individualism and commitment in American life. Berkeley: University of California Press.

Bowles, S. And Gintis, H., 1998. "The moral economy of communities: structured populations and the evolution of pro-social norms",
Evolution and Human Behavior, 19 (1), 3-25.

Bowles, S. And Gintis, H., 1999. "Is equality passé? Homo reciprocans and the future of egalitarian politics", Boston Review, 23 (6), 1-22.

Bowles, S. AND Gintis, H., 2000. "Reciprocity, self interest and the welfare state", Nordic Journal of Political Economy, 26 (1), 33-53.

Bowles, S. ANd Gintis, H., 2002. "Social capital and community governance", Economic Journal, 112 (483), 419-436.
Bowles, S. AND Gintis, H., 2005.

"Social capital, moral sentiments, and community governance". In: $\mathrm{H}$. Gintis, S. Bowles, R. Boyd and E. Fehr, eds. Moral sentiments and material interests: the foundations of cooperation in economic life. Cambridge, MA: The MIT Press, 379-398.

Brennan, G., 1996. "Selection and the currency of reward". In: R. E. Goodin, ed. The theory of institutional design. Cambridge: Cambridge University Press, 256-275. 
Buchanan, J. M., 1999. The collected works of James M. Buchanan. Indianapolis: Liberty Fund.

Christiano, T., 2004. "Is normative rational choice theory self-

defeating?" Ethics, 115 (1), 122-141.

Elster, J., 1998a. "Introduction". In: J. Elster, ed. Deliberative democracy. Cambridge: Cambridge

University Press, 1-18.

Elster, J., 1998b. "Deliberation and constitution making". In: J. Elster, ed. Deliberative democracy. Cambridge: Cambridge University Press, 97-122.

ENGElen, B., 2008. Rationality and institutions: on the normative implications of rational choice theory. Saarbrücken: VDM Verlag Dr. Müller.

FeHr, E. AND Gächter, S., 2000. "Fairness and retaliation: the economics of reciprocity", Journal of Economic Perspectives, 14 (3), 159-181.

FeHr, E. AND Gächter, S., 2002. "Altruistic punishment in humans", Nature, 41, 137-140.

Gintis, H., 2000. "Beyond Homo economicus: evidence from experimental economics", Ecological Economics, 35, 311-322.

GinTIS, H., 2003. "Solving the puzzle of prosociality", Rationality and Society, 15 (2), 155-187.

Gintis, H., Bowles, S., Boyd, R. AND FeHR, E., 2005. "Moral senti- ments and material interests: origins, evidence, and consequences". In: H. Gintis, S. Bowles, R. Boyd and E. Fehr, eds. Moral sentiments and material interests: the foundations of cooperation in economic life. Cambridge, MA: The MIT Press, 3-39.

Hausman, D. M., 1998. "Rationality and knavery". In: W. Leinfellner and E. Köhler, eds. Game theory, experience, rationality: foundations of social sciences, economics and ethics in honor of John C. Harsanyi. Dordrecht: Kluwer, 67-79.

Hume, D., 1964. Essays, moral, political and literary. Oxford: Oxford University Press.

KAHAN, D. M., 2005. "The logic of reciprocity: trust, collective action, and law". In: H. Gintis, S. Bowles, R. Boyd and E. Fehr, eds. Moral sentiments and material interests: the foundations of cooperation in economic life. Cambridge, MA: The MIT Press, 341-378.

Le Grand, J., 2003. Motivation, agency, and public policy: of knights and knaves, pawns and queens. Oxford: Oxford University Press.

MäKI, U., 2005. "Models are experiments, experiments are models", Journal of Economic Methodology, 12, 303-315.

McMillan, D. W. and Chavis, D. M., 1986. "Sense of community: a definition and theory", Journal of Community Psychology, 14 (1), 1-23.

Miller, D., 1990. Market, state, and community: theoretical foundations of market socialism. Oxford: Clarendon Press.

Pettit, P., 1996. "Institutional design and rational choice". In: R. E. Goodin, ed. The theory of institutional design. Cambridge: Cambridge University Press, 54-89.

Pettit, P., 2001. "The virtual reality of Homo economicus". In: U. Mäki, ed. The economic world view: studies in the ontology of economics. Cambridge: Cambridge University Press, 75-97.

Pettit, P., 2002. Rules, reasons, and norms. Oxford: Clarendon Press.

Rawls, J., 1999. The law of peoples. Cambridge: Harvard University Press.

Richerson, P. J., Boyd, R. T. AND Henrich, J., 2003. "Cultural evolution of human cooperation". In: P. Hammerstein, ed. Genetic and cultural evolution of cooperation. Cambridge, MA: The MIT Press, 357-388.

Rousseau, J. J., 1983. On the social contract; discourse on the origin of inequality; discourse on political economy (Trans. D. A. Cress, Intro. P. Gay). Indianapolis, IN: Hackett Publishing Company.

Sen, A., 1987. On ethics and economics. Oxford: Basil Blackwell.

Williams, B., 1990. "Internal and external reasons”. In: P. K. Moser, ed. Rationality in action: contemporary approaches. Cambridge: Cambridge University Press, 387-397. 